\title{
PERANCANGAN SISTEM INFORMASI KEUANGAN PADA TOKO AYAM POTONG ZARMI BERORIANTASI OBJEK
}

\author{
Arman $^{1)}$, SophanSophian ${ }^{2)}$, AnisaSahputri ${ }^{3)}$ \\ ${ }^{1,2,3}$ STMIK Indonesia Padang, sistem Informasi \\ email :arman@stmikindonesia.ac.id, SophanSophian@stmikindonesia.ac.id, AnisaSahputri@gmail.com
}

\begin{abstract}
Abstrak
Chicken Piece Zarmi shop is the company enganged in the pice the chicken. This shop do the selling and purchase processing data still manually, there are the pilling file doesn't arrange clearly doesn't have media processing data yet. Seeing the problem then it proposed to build the financial report application at chicken piece zarmi shop with Microsoft Visual Basic C\# programming languages and with saving the data to database. it can be easily the owner to do selling and purchase processing data quickly and accurately. The advantages this application is the problem will solve the well and it will increase the service to the people so quickly, effective, effisien. So that the duplicate data won't find out when the owner want to be recording the data and the data stil stored well.
\end{abstract}

\section{Keyword : application, selling and purchase processing data.}

\section{PENDAHULUAN}

Kemajuan ilmu pengetahuan dan teknologi saat ini terasa sangat pesat dan sejalan dengan perkembangan teknologi saat ini, sehingga masalah yang timbul semakin kompleks, baik yang terjadidalam dunia bisnis maupun informasi.[1] Hal ini memacu kita untuk mengikuti perkembangan teknologi informasi tersebut, karena teknologi informasi dapat membantu dalam kebutuhan kita seharihari, dengan memakai suatu alat bantu yaitu komputer.[2] Alat tersebut mampu membantu manusia dalam semua bidang pekerjaan, seperti memenangani dan memproses data jumlah yang banyak dengan kecepatan yang tinggi dan menghasilkn informasi yang dibutuhkan dengan tepat dan akurat, sehingga mampu menyangi kemampuan manusia dalam hal kecepatan, ketelitian, serta penyimpanan data.Sistem informasi mutlak diperlukan dalamrangka memenuhikebutuhan pokok sehari- haridisemua lapisan masyarakatbaikmasyarakatyang tingkatekonomidanpendidikannya rendahsampaidenganmasyarakatyang tingkatekonomidanpendidikannyatinggi.Semaki $\mathrm{n}$ tinggitingkatekonomidanpendidikan seseorang makasemakin tinggipulakebutuhan informasinya.[3]

Pada saat sekarang ini persaingan didunia bisnis semakin bersaing, Agar dapat bertahan ditengah persaingan usaha yang semakin ketat, sangat diperlukan sebuah system yang dapat melakukan pengolahan data pembelian dan penjualan secara cepat dan tepat, hal ini akan mempermudah pengelola atau owner untuk mengontrol stok yang tersisa dari pembelian perbulan, dari hal tersebut akan terlihat alur toko dan laporan keuangan yang jelas.

Untuk itu peneliti mencoba memecahkan masalah yang ada pada usaha Ayam Potong Zarmi. Toko ini bergerak di bidang penjualan ayam potong, yang mana setiap harinya melakukan transaksi yang tidak sedikit dan semua itu dilakukan pembukuan secara manual. Sehingga bisa menimbulkan kesalahankesalahan selama prosespembuatan laporan keuangan,seperti:, selama transaksi terjadi kesalahn dalam pencatatan dana, dan kekeliruan dalam menjumlahkan maupun mengalikan harga-harga ayam potong dalam jumlah yang besar. Untuk mendapat data stock ayam pun harus di dapat dengan menghitung ayam yang ada terlebih dahulu. Hal ini tentu akan 
menimbulkan masalah dalam hal keakuratan, kecepatan dan ketepatan dalam menghasilkan informasi, apa lagi transaksi itu dilakukan dalam jumlah besar dan terja di secara berulang-ulang. Untuk mengatasi hal tersebut, maka peneliti mencarikan jalan keluar atau solusi dengan merancang aplikasi

sistem informasi yang terotomatisasi,dengan menggunakan aplikasi system informaasi ini akan memberikan hasil yang lebih cepat, tepat dan akurat, dan semua masalah yang terjadi dapat teratasi dengan baik, sehingga dalam membuat laporan sudah tepat waktu dan efisien.

Sistem informasi adalah suatu sistem di dalam suatu organisasi yang mempertemukan kebutuhan pengolahan transaksi harian, mendukung operasi, bersifat manajerial dan kegiatan strategis dari suatu organisasi dan menyediakan pihak luar tertentu dengan laporan - laporan yang diperlukan.(3)

Sehingga Sistem informasi yang dibangun dapat dikemas agar dapat digunakan untuk mendapatkan informasi lebih cepat dan tepat.[4]. Dan memberikan pelayanan kepada pelanggan dan kepaa konsumen dalam proses pelayanannya dapat lebih mudah dan cepat.

\section{METODE PENELITIAN}

Metodepenelitianyang dalammenyelesaikan penelitian iniadalah sebagaiberikut[5]:

a. TahapStudiLiteratur, Studi literaur inidilakukan dengan pencaandatadanpengumpulanartikel,jurnal,buk ureferensi,tutorialdan sumber lain.

b.Tahap PengumpulanData,Pengumpulan data merupakansalahsatuhalpenting dalam penelitian ini.Data-datasepertihotel, tempatwisata, lokasiATMdanlain-lain akan dikumpulkan secaralangsung dikota Bukittinggi, sehingga keakuratan data dapat dimaksimalkan.Selainitu,penulis jugaakan bekerjasamadengan instansi pemerintah yang terkait demi memudahkan pengumpulandata.
c.Tahap

Perancangan Aplikasi,Dalamtahapanini, mulaimelakukan perancangan aplikasi Sistem Informasi Geografis Pariwisata kota Bukittinggi berdasarkan referensi yang sudahdidapatkandaristudiliteratur sertadaridata-datayangsudahdidapatkan.

d.TahapSimulasi danAnalisis,Aplikasi
yang telahdirancang mula-mulaakan
disimulasikan dengan AndroidSimulator
untukmelihathasilnya.Setelahituaplikasi
tersebutdiubah menjadisebuah paket instalasiuntukdiuji pada perangkat smartphone Android. Hasildarisimulasi danpengujianinikemudianakandianalisis untukmendapatkansebuah kesimpulan.

e. TahapSurvey, Padatahapanini,akan dilakukansurvey terhadapbeberapa wisatawan untuk dimintai pendapatnya terhadapaplikasi ini.

Metodologiyang digunakandalam pengembangan perangkatlunak (software) adalah SDLCyangseringdigunakan antaralainWaterfalldanPrototyping.

ModelWaterfalladalah salah satumodel SDLCyangseringdigunakan atausering disebut juga dengan model konvensionalatauclassic lifecycle. Metode ini merupakanpemodelan perangkatlunak(software) dengan menitikberatkanpadaaksi-aksi yang dilakukandisejumlahtahap,dimana setiaptahap akanmenghailkan (output) dengan bentukyang berorientasiobjek [6].

\section{HASIL DAN PEMBAHASAN}

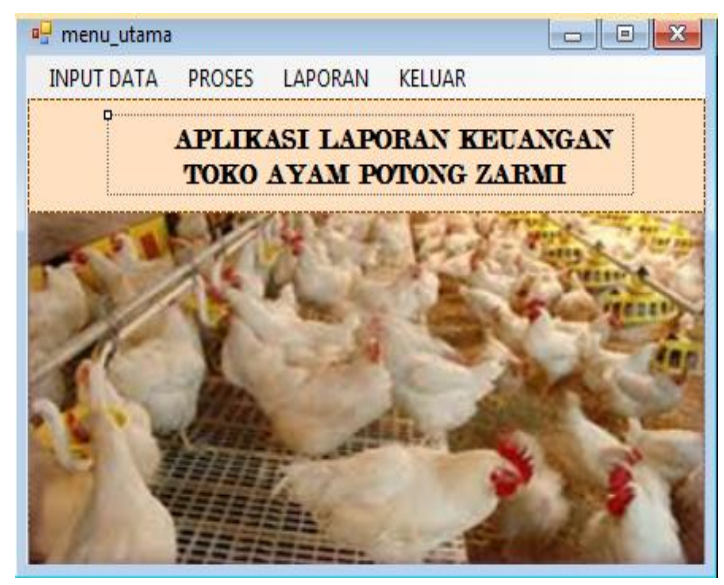

Gambar 1.Menu Utama. 
a.

\section{Form Login}

Merupakan tempat admin menginputkan username, password untuk masuk kemenu utama. Untuk lebih jelasnya dapat dilihat pada gambar dibawah ini :

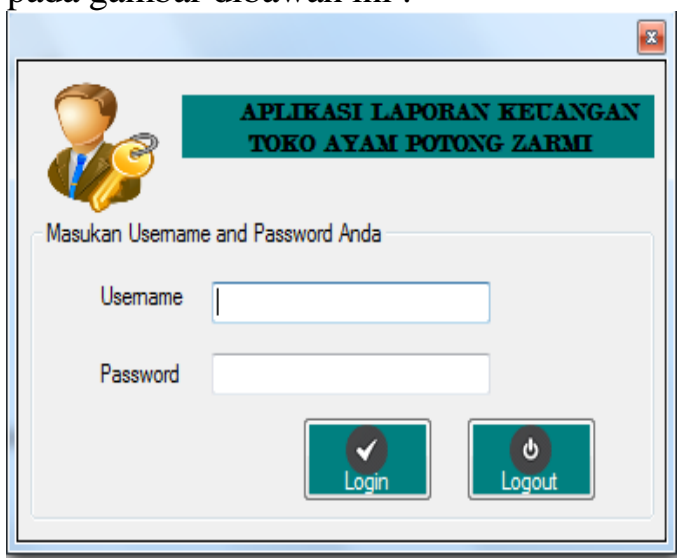

Gambar 2. Halaman Login

\section{Input Data}

a. Input Data Pelanggan

Form ini merupakan form untuk mengentrikan data pengelola data pelanggan yang dilakukan user. Data yang dientrikan adalah kd pelanggan, nama pelanggan, alamat, notelp.Form input data pada Aplikasi Laporan Keuangan pda toko ayam poton zarmi sebagai berikut :

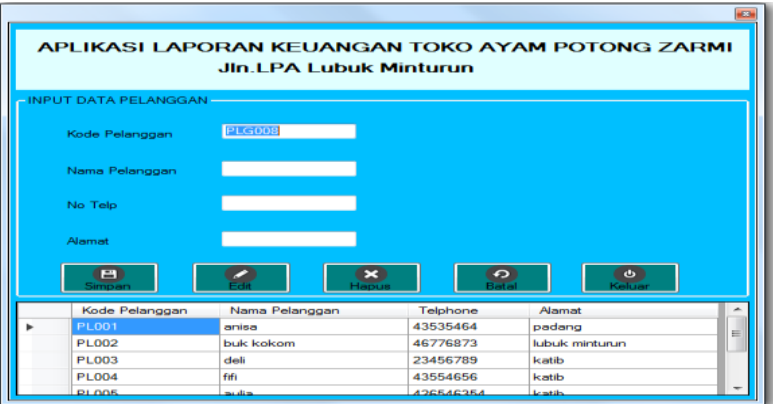

Gambar 3. Form Entri Data Pelanggan.

\section{b. Input Data Ayam}

ini merupakan form untuk mengentrikan data pengelola data Ayam yang dilakukan user. Data yang dientrikan adalah kode ayam, jumlah ayam,harga ayam.Form input data pada Aplikasi Laporan Keuangan pada toko ayam potong zarmi sebagai berikut :

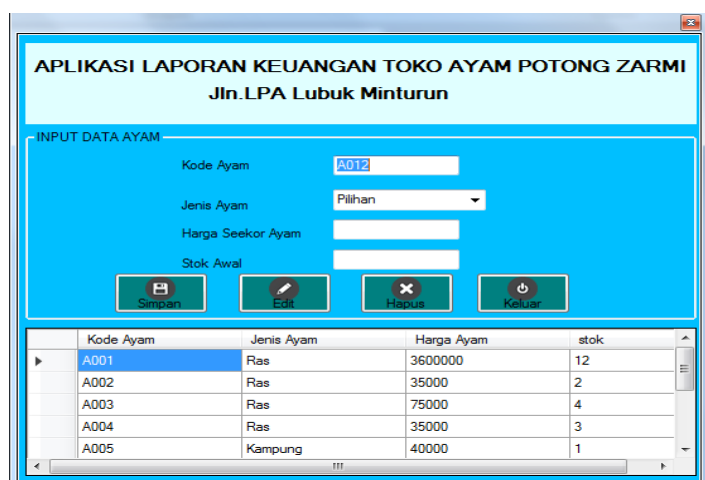

Gambar 4.Form Entri Data Pelanggan.

\section{c. Input Data Pemasok}

Form ini merupakan form untuk mengentrikan data pemasok. Data yang dientrikan adalah $\mathrm{kd}$ pemasok, nama_pemasok ,alamat, no telpn.Form input data pemasok pada aplikasi laporan keuangan tpada toko ayam potong zarmi dapat dilihat pada gambar dibawah ini :

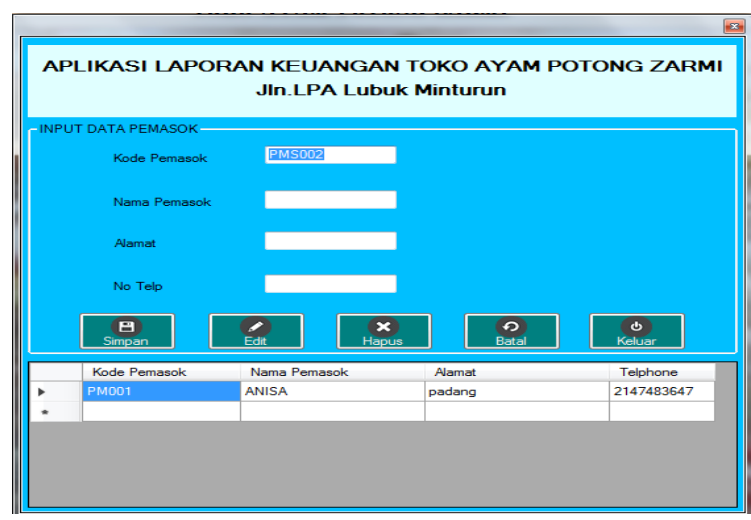

Gambar 5. Form Entri pemasok.

\section{d. Entri Data Stok Masuk}

Form ini merupakan form untuk mengentrikan data stok masuk. Data yang dientrikan adalah No nota, kd pemasok,nama pemasok, kd ayam jumlah stok.Form input data penjulan pada aplikasi laporan keuangan toko ayam potong zarmi dapat dilihat pada gambar dibawah ini : 


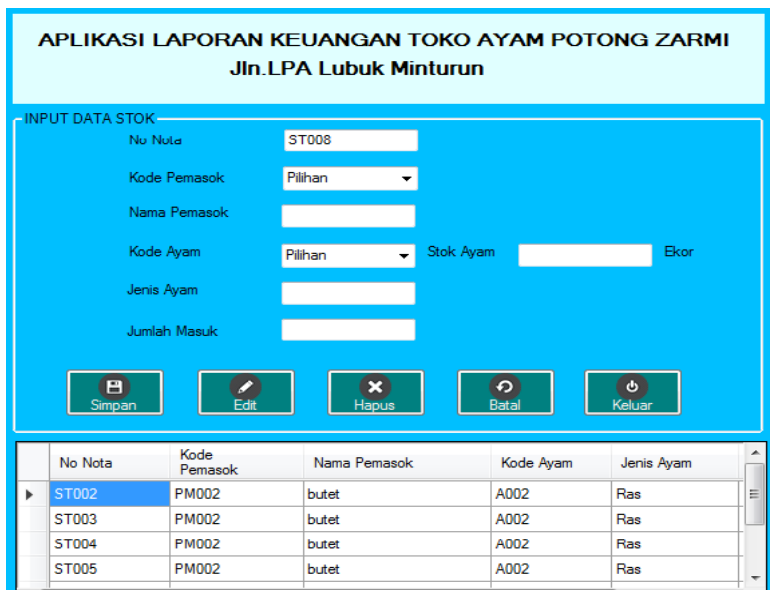

Gambar 6. Form Entri Data stok Masuk .

\section{Proses}

Dalam Merancang Aplikasi Laporan Keuangan pada toko ayam zarmi menggunakan bahasa

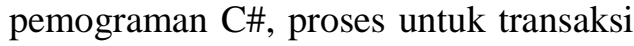
penjualan ayam dapat dilihat pada gambar dibawah ini :

\section{a. Entri Data Penjualan}

Form ini merupakan form untuk mengentrikan data penjualan. Data yang dientrikan adalah No Transaksi, nota penjualan, kode pelanggan ,nama pelanggan , kode ayam, tanggal penjualan, jumlah beli,harga ayam.

Form input data aplikasi laporan keuangan toko ayam potong zarmi dapat dilihat pada gambar dibawah ini :

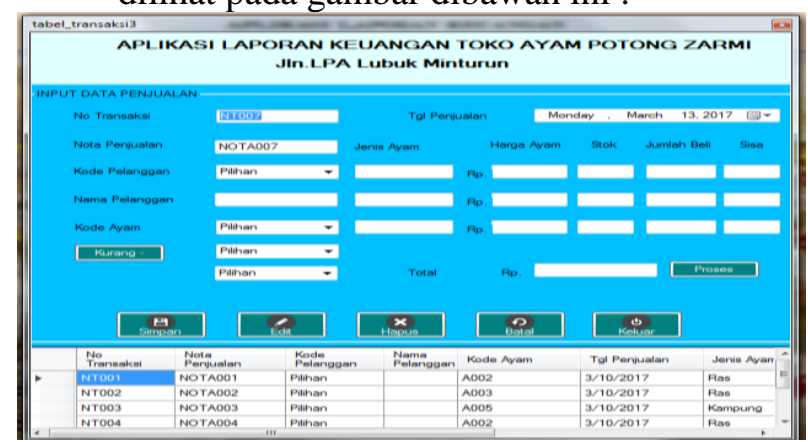

Gambar 7. Form Proses Transaksi Penjualan ayam.

\section{b. Entri Data Pembelian Stok Ayam}

Form ini merupakan form untuk mengentrikan data penetasan. Data yang dientrikan adalah No nota, kode pemasok, nama pemasok ,banyaknya, nama barang, harga,jumlah tanggal pembelian.

Form input data aplikasi laporan keuangan toko yam potong zarmi dapat dilihat pada gambar dibawah ini :

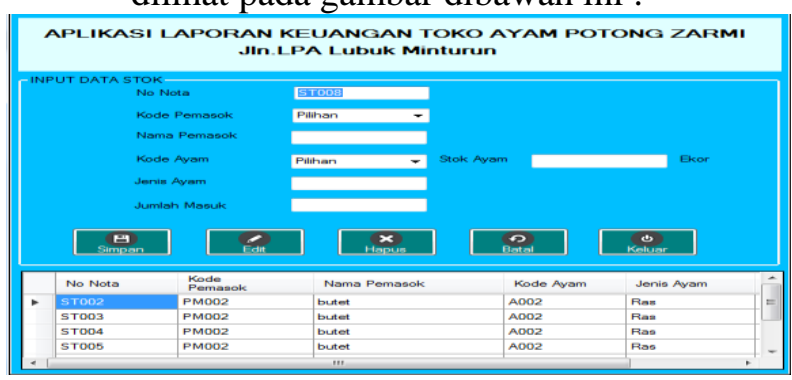

Gambar 8. Form Entri Data Stok Masuk.

\section{Output}

Dalam sub menu laporan terdiri dari beberapa modul yaitu laporan data pembelian laporan penjualan, Modulmodul laporan tersebut yaitu:

\section{a. Laporan Data Pembelian}

Laporan data pembelian dapat dilihat pada gambar dibawah ini :

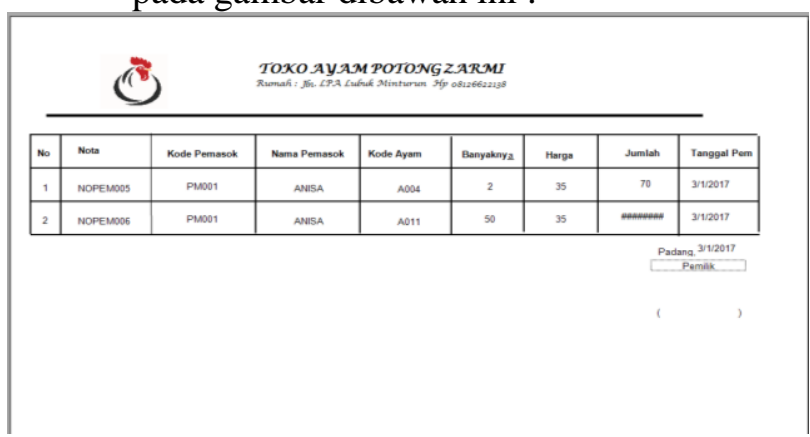

Gambar 9.Laporan Data Pembelian Perhari.

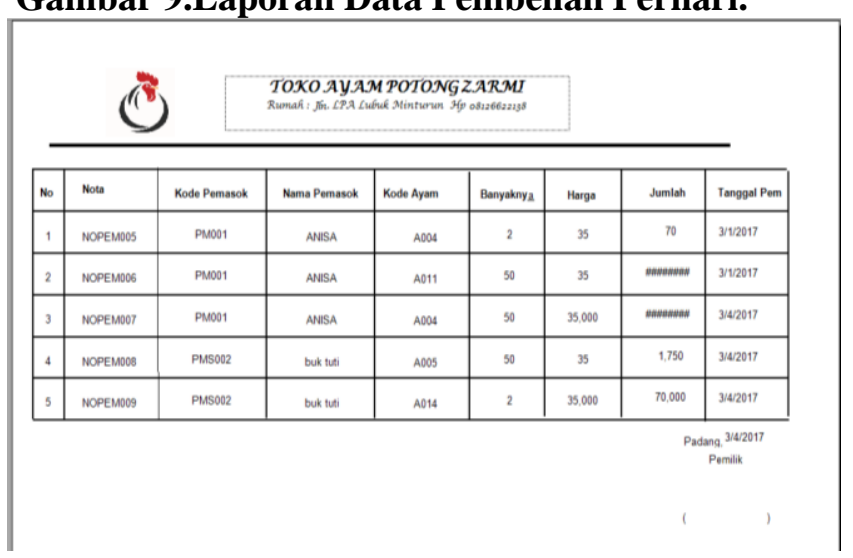

\section{Gambar 10.Laporan Data Pembelian Perminggu.}




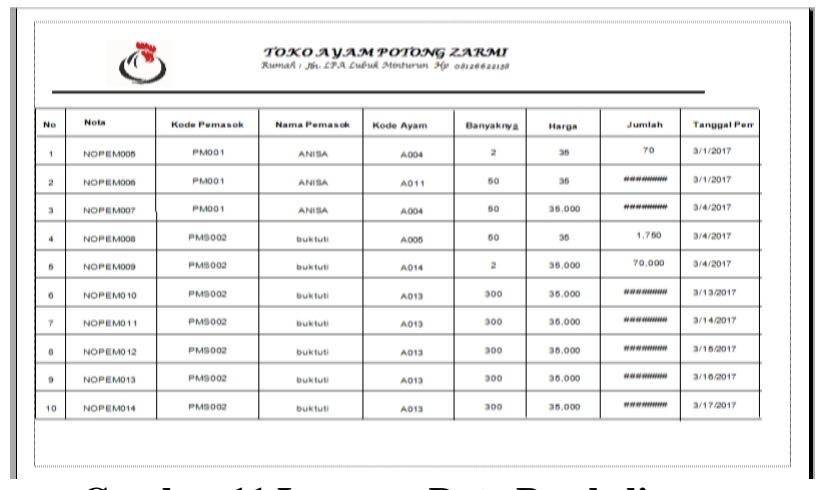

Gambar 11.Laporan Data Pembelian Perbulan.

\section{b. Laporan Penjualan} Sebelum laporan dimunculkan, maka akan tampil form laporan penjualan, seperti yang terlihat pada gambar dibawah ini:

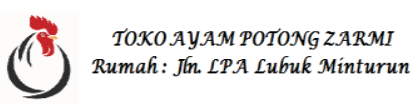

\begin{tabular}{|c|c|c|c|c|c|c|c|}
\hline fia No Transaks & Nota Penjuahn & KodePelangag & Kodetefyam & Tanggal Penjuabn & Jumbabeti & Harga Atram & Total \\
\hline Mroon & Votanou & poov1 & Ano1 & 928282016 & 3 & 35.000 & 105,000 \\
\hline nroos & WoTA002 & p10033 & AnO4 & 100320216 & 5 & 20 & 100 \\
\hline mroor & Notano & 20001 & A001 & 10442016 & 30 & 30.000 & 900.000 \\
\hline 4 sroos & votanous & 20001 & A001 & 1042015 & 5 & 40,000 & 200,000 \\
\hline 5 |ro⿰氵6 & WOTAON5 & $P 1002$ & An04 & 1215152016 & 56 & 12 & 672 \\
\hline 5 |rroor & Wotanos & plo033 & A0008 & |21152016 & 5 & $2,1,111$ & 105,555 \\
\hline 19008 & WOTANOT & ploor & 2001 & 121520216 & 2 & 25 & 50 \\
\hline
\end{tabular}

\section{Gambar 12. Form Penjualan ayam.}

Pada formlaporan penjualan tersedia parameter untuk menentukan laporan penjualan berapa yang ingin kita cetak, maka akan ditampilkan pada monitor laporan penjualan berdasarkan penjualan pada ayam .

\section{SIMPULAN}

Berdasarkan hasil analisis dan pembahasan sebelumnya yang dilakukan pada Aplikasi Laporan Keuangan pada Toko Ayam Potong Zarmi, maka dapat diambil kesimpulan, yaitu :

1. Dengan menggunakan sistem yang terkomputerisasi, maka pengolahan data pada toko ayam potong zarmi dilaksanakan dalam waktu yang relatif singkat, sehingga informasi yang diperoleh akan lebih akurat. Disamping itu juga penyimpanan data akan lebih terjamin, aman dan tidak banyak memakan tempat.

2. Dengan adanya sistem yang diusulkan maka dapat menghemat banyak tempat ruang kerja karena sudah menggunakan database.

3. Dengan adanya sistem yang diusulkan maka akan lebih memudahkan dalam proses pengolahan data dan juga penyusunan laporan pada aplikasi pengolahan data pada toko ayam potong zarmi, sehingga mengurangi tingkat kesalahan yang ada.

4. Aplikasi Laporan keuangan pada toko ayam potng zarmi memiliki database yang mampu menampung data serta informasi yang diolah dan dibutuhkan bagi pemilik.

5. Laporan keuanagan pada toko ayam potong sesuai dengan tanggal transaksi penjualan setiap hari, sehingga data untuk laporan dapat tersusun dengan rapi serta urut.

\section{DAFTAR PUSTAKA}

[1] N. Susanti, "PEMANFAATAN TEKNOLOGI INFORMASI UNTUK SISTEM INFORMASI MANAJEMEN SEKOLAH : STUDI KASUS PADA SMA 78 JAKARTA Ayuliana; Neva; Novia Susanti; Fahreza," ComTech Vol.2 No. 2 Desember 2011 1172-1191, vol. 2, no. 2, pp. 1172-1191, 2011.

[2] R. H. Sri Rezeki Candra N1), Nopriyadi "PERANCANGAN SISTEM INFORMASI ADMINISTRASI," Tek. FTUP,Faktor Exacta, vol. 28, no. 1, pp. 146-155, 2015.

[3] A. Lipursari, "Peran Sistem Informasi Manajemen (Sim) Dalam Pengambilan Keputusan," J. STIE SEMARANG, vol. 5, no. 1, pp. 26-37, 2013. 
[4] S. Informasi, P. Digital, J. Sistem, I. Fakultas, I. Komputer, and U. Sriwijaya, "PENGEMBANGAN MODEL SISTEM INFORMASI PERPUSTAKAAN DENGAN TEKNOLOGI INFORMASI BERBASIS WIRELESS APLICATION PROTOCOL (WAP) PADA UNIVERSITAS SRIWIJAYA," J. Sist. Inf. (JSI), vol. 4, no. 1, pp. 425-436, 2012.

[5] P. S. Informasi and S. Jayanusa, "IMPLEMENTASI SISTEM INFORMASI GEOGRAFIS PARIWISATA KOTA BUKITTINGGI," J. sains dan Inform. Res. Sci. Inform., vol. 2, pp. 126-141, 2017.

[6] R. Susanto, A. D. Andriana, R. Susanto, and A. D. Andriana, "Perbandingan Model Waterfall Dan Prototyping," Maj. Ilm. UNIKOM, vol. 14, no. 1, pp. 41-46, 2016. 